\title{
O Binômio Arte-Moda: Estratégia De Museu Para a Tendência da Moda.
}

Janaina Luisa da Silva Moroni

Mestre, Universidade Federal do Rio Grande do Sul / janaina.moroni@gmail.com Orcid: 0000-0002-5972-712X /http://lattes.cnpq.br/6025190256907879

Yazmin Pamela da Silva Moroni

Doutoranda, Universidade Católica Argentina / moroni.yazmin@gmail.com Orcid: 0000-0002-0720-9769/ http://lattes.cnpq.br/1043733356669288

Edval Rodrigues de Viveiros

Doutor, Université Paris 8 /Laboratoire Paragraphe (Vincennes Sain-Denis) França / edvalrv@hotmail.com Orcid: 0000-0002-4107-0860 /http://lattes.cnpq.br/8070036902250385 


\title{
O Binômio Arte-Moda: Estratégia De Museu Para a Tendência da Moda.
}

\begin{abstract}
RESUMO
Este trabalho, financiado pela Coordenação de Aperfeiçoamento de Pessoal de Nível Superior (CAPES Brasil), aborda os vínculos entre arte, moda e museu a partir de uma experiência empírica concreta. Apresenta-se a identificação das estratégias criativas italianas da nossa contemporaneidade, sob o aspecto da sociologia, estudos estratégicos e design. Assim, oferecer um repertório de conhecimentos aos profissionais, estudantes de arte, comunicação, comércio criativo internacional e design de joias. Mostrar que é possível atender ao mercado de luxo com o binômio arte-moda de valorização recíproca, como o caso do Museu Bardini e Joias Marco Baroni.
\end{abstract}

Palavras-chave: Museu, Arte-Moda, Sociologia. 


\title{
The Binomial Art-Fashion: Museum Strategy For The Trend of Fashion.
}

\begin{abstract}
This paper sponsored by the Coordination for the Improvement of Higher Education Personnel (CAPES Brasil), we have investigated the relation of art, fashion and museums using an concrete empirical experience. We present the identification of Italian creative strategies of our contemporaneity, under the aspect of sociology, strategy studies and design. Therefore, to offering the knowledge base for professionals and students in art, in communication, and in international creative trade and jewelry design. It was also possible to demonstrate that it satisfies the luxury market with the binomial art-fashion of mutual appreciation as the experience of the Bardini Museum and Marco Baroni jewellery.
\end{abstract}

Keywords: Museum, Art-Fashion, Sociology. 


\section{INTRODUÇÃO}

O Museu Stefano Bardini, faz parte da rede italiana de museus da cidade de Florença, região da Toscana, denominada de Museu Civici Fiorentini, é dirigido por Antonella Nesi, responsável pela qualidade e divulgação do espaço com obras que abrangem desde coleções de tapetes, móveis, sapatos, armamentos, pinturas, molduras, esculturas, maquetes e elementos de arquitetura. A seleção por esse museu, para esse estudo, se deve a sua dedicação em oportunizar espaços reflexivos e de aprendizagem. Integrando a antiguidade com a modernidade. Assim, no mês de dezembro do ano de 2014, através de financiamento de pesquisa internacional CAPES Brasil, foi possível conferir de perto o seu trabalho, especificamente na exposição da sala Chiostrina, com a coleção de dezoito esculturas circulares, ver Figura 1, que inspiram o trabalho do joalheiro toscano Marco Baroni.

Figura 1: Sala Chiostrina do Museu Stefano Bardini

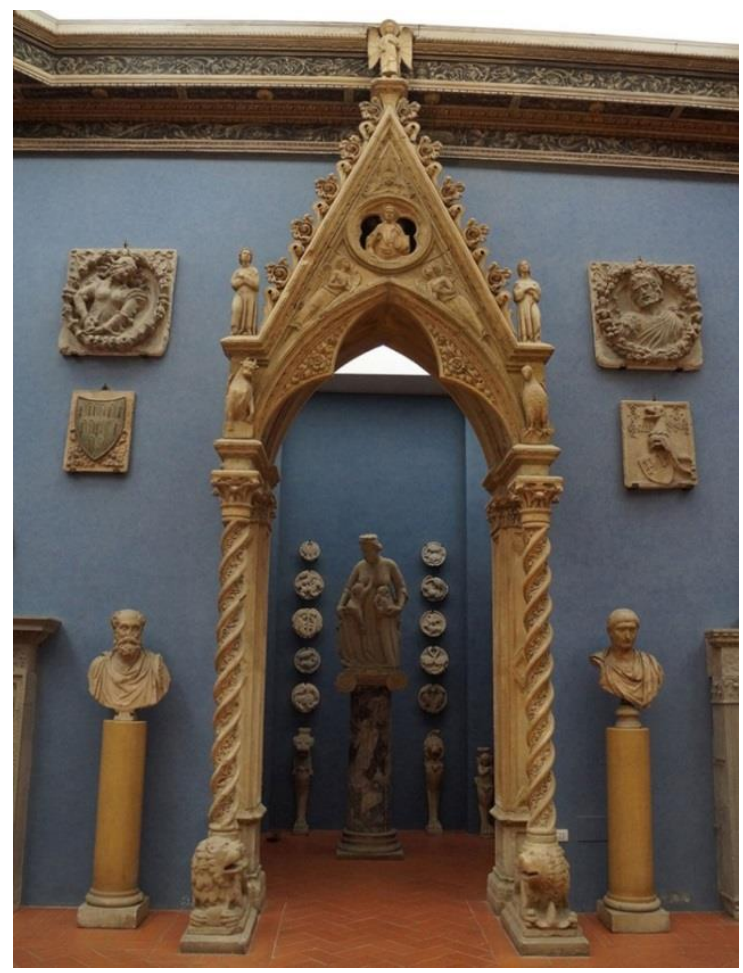

Fonte: Acervo dos autores (2014) 
De acordo com Piscitelli (2011), os acessórios foram criados com o intuito de ser um complemento para roupa, e continuam até os dias de hoje sendo utilizados, mesmo com modificações dos elementos ao longo do tempo, podemos citar exemplos como os anéis, pingentes, brincos, relógios, etecetera.

Cabe salientar que a moda é um fenômeno cultural com o qual estamos em contato de forma diária e permanente, pois a cultura é um requisito fundamental para a existência de uma sociedade, é o conceito básico que define a nossa identidade. De acordo com Becker (1982) e Crane (2011), a moda e a arte são formas de cultura material. Segundo Marín (2011), define a cultura devido a tudo aquilo que abrange o saber, arte, moral, direito, costumes e outras capacidades adquiridas pelo homem como membro de uma sociedade. Em definitiva são esses costumes e condutas que geram a moda. É esta a existência de regras não estritas, pois 0 indivíduo pode ter formas parecidas sem ser exatamente igual. O que devemos recordar é que não podemos estar fora do seu âmbito de influência, pois faz parte da sociedade.

Certamente, as joias fazem parte da moda pois são a representação dos pensamentos do homem e compõem o visual da identidade do indivíduo. Nesse sentido, os autores Barthes (2003) e Avellaneda (2013) consideram as joias objetos da moda e por isso também seguem tendências. Os acessórios, em particular, segundo Piscitelli (2011) têm a tendência de se instalar na cultura geral imposto pela moda.

Esta ligação da arte com a moda retrata a realidade italiana pelo seu extenso legado histórico ainda presente e visitável. A Itália respira arte, a sua moda reflete isso. O que constata a autora Sensini (2013), ao citar Prada: "a moda fala uma língua de imagens que tem a prerrogativa de 
representar emblematicamente o contexto social no qual ela é produzida, transformando-se com este, o espelho e a projeção ideal". Por isso, é tendência o binômio arte-moda, como o exemplo dado pela autora Avellaneda (2013), Chanel-Picasso, Schiaparelli-Dali, Ives Saint Laurent e sua série de homenagem a Mondrian são testemunhas desta tendência.

Apesar dos italianos respirarem arte de seus antepassados sabem relacionar a arte antiga com a contemporaneidade. De acordo com Laghezza \& Lucchese (2016) o design italiano é nutrido de reciprocidade com a atualidade.

Assim, apresenta-se a metodologia de estudo, o resultado do trabalho de parceria entre museu e joalheria; as conclusões acompanhadas de reflexões e sugestões para estudantes e profissionais de comércio criativo internacional, comunicação e design de moda.

\section{FOCO DA PESQUISA}

A metodologia é básica e aplicada. Parte dos conhecimentos expostos teoricamente nos quais são verificados a observação da realidade do legado da arte italiana na atualidade, representada na moda contemporânea, joias. Assim, adquirir o modo estratégico criativo usado para atender a tendência do binômio artemoda. Os meios utilizados para obter a informação foram de pesquisa documental e de campo. A pesquisa inicia com uma revisão documental que gera parâmetros de observação e permite a construção do marco teórico; continua com uma análise de campo ao aplicar instrumentos de coleta de informações, como entrevistas e fotografias, acompanhadas das observações do trabalho de museu e do joalheiro. A investigação é centrada na coleta e análises de informação do tipo qualitativa. 


\subsection{Objetivo e modelo metodológico}

Como é possível visualizar se construiu um marco teórico no qual se conheceu, brevemente, a relação da arte com a moda. Despertando a curiosidade de conhecer o pensar criativo estratégico de quem dirige o museu e quem faz joias na cidade do berço do renascimento italiano. Assim, foi necessário conhecer o projeto do Museu Stefano Bardini.

Com este fim, definiu-se um esquema metodológico centrado no seguinte objetivo: observar e identificar a estratégia italiana em seguir o binômio arte-moda. Museu Stefano Bardini com a linha Marco B. Este objetivo foi desenvolvido através da aplicação das técnicas metodológicas que se demonstram a seguir.

\subsection{Unidades de análise}

As unidades de análises são: A Série Fornelle e as joias Marco B. De acordo com Nesi (2011), o objeto de nosso estudo cientifico é identificado como sendo "Maestranza Genovese - Pisane, Serie Fornelle", estes são do século XIV, e possuem o código inventariado de número 221-238. Estas, 18 fornelle, estão posicionadas na parede da Chiostrina. Nome da pequena sala localizada ao fundo da Sala della Carità do Museu Stefano Bardini.

O museu está localizado na via dei Renai 37, Ponte alla Grazie, Bairro San Niccolò, região conhecida como Oltrarno, na expressão "Diladdarno" para se referir a parte esquerda do rio Arno. Atualmente, também se utiliza a expressão francesa geográfica "rive gauche" para o termo comum de sinônimo de região intelectual, artístico, e também bohèmien. Na mesma rua, no número 3, está presente a bottega do joalheiro toscano. 


\subsection{Técnicas}

A técnica empregada nesta pesquisa é de aporte teórico da sociologia, design e de estudos estratégicos. O objetivo é verificar a estratégia criativa para unir Arte antiga com a Moda da contemporaneidade do binômio Arte-Moda.

Para isso, selecionou-se o joalheiro Marco Baroni, responsável por associar design de joias, arte, e contemporaneidade, conhecido por ter peças expostas no Museu Bardini e Palazzo Pitti, da cidade de Florença, e participações em exposições internacionais de moda para representar o design de joias italiano.

\section{BINÔMIO ARTE-MODA: MUSEU STEFANO BARDINI E MARCO B.}

O gosto é mutável e a moda arbitraria. Se a indumentária confirma determinados rumos, [...] as joias são também referências de tendências das sociedades (Avellaneda, 2013, p.27) [...] a tendência é também que arte e a moda andem juntas (op. cit., p.28).

De acordo com Avellaneda (2013), as tendências são as convergências do gosto coletivo e são oriundas de nós mesmos como sociedade. As tendências são desejos generalizados ou compartilhados. Para o sociólogo Guillaume Erner são "focalizações do desejo pelas quais uns indivíduos, distintos de uns e outros, sem ter estado de acordo, mostram ter os mesmos desejos" (Erner, 2010, p. 9). Entretanto, para Piscitelli (2011), a moda transmite mais que uma tendência e sim proporciona informação valiosa sobre a época, estado social e emocional do indivíduo na sociedade.

A tendência é também que a arte e a moda andem juntas. Como o exemplo, dito anteriormente, o binômio Chanel-Picasso, é testemunha desta afirmação (Avellaneda, 2013). Estas uniões adicionam valor agregado, e transmitem 
com facilidade o aumento da percepção das qualidades da marca e da instituição de arte, tornando a seleção de determinado museu e marca de moda, predileta e memorável entre as concorrentes. Nos estudos de Rumschinsky (2009), afirma que o indivíduo faz associação da imagem famosa (comportamento, estilo, pensamentos) com o produto de venda, isso ocorre pelo prévio conhecimento das características do famoso que o induz a desejar o produto e pagar a mais por ele. Para Barthes (1964), os signos da publicidade são intencionais, por isso, claramente definidos, ou compreendidos. De acordo com Gemma Penn (2000, p. 325 e 329), a intenção é de promover a fama e as vendas do produto, e exemplificam apresentando o anuncio de um perfume da empresa de moda Givenchy, intitulado de Organza. Formato do vidro do perfume e da modelo anunciante, com formas que lembram a arquitetura antiga: a cariátide. Esta estratégia para recordar o período clássico grego. Dar a ideia de ser produto destinado a indivíduos clássicos. A estratégia do museu é passar diversas mensagens de valorização da arte, do próprio museu, do legado da cultura italiana que faz parte da tendência do binômio arte-moda.

O Joalheiro toscano Marco Baroni está habituado em unir obras artísticas em seus trabalhos com visão contemporânea, por isso foi convocado pela Diretora do Museo Stefano Bardini, Antonella Nesi, para realizar joias inspiradas em 18 esculturas circulares presente na sala Chiostrina. Ver Figura 2. 
Figura 2: Serie Fornelle do Museu Stefano Bardini

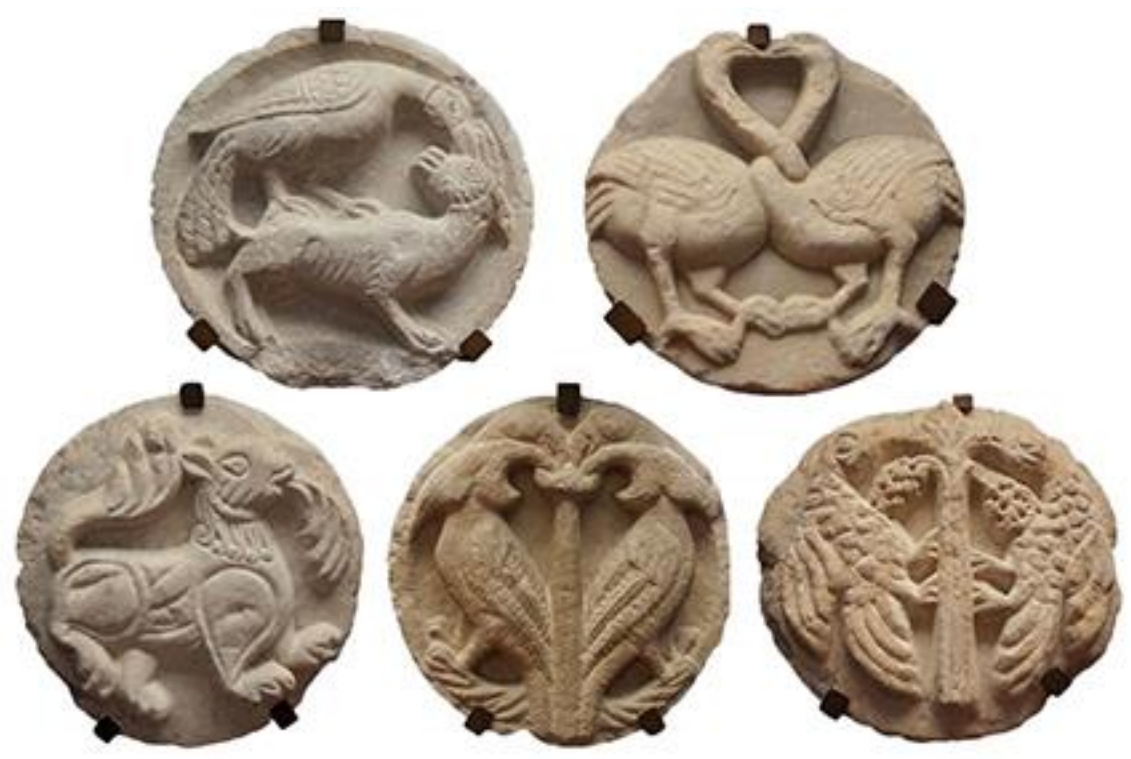

Fonte: 1 Acervo dos autores (2014)

Em relação ao formato circular dessas esculturas identificadas de Maestranza Genovese-Pisane do século XIV, seguem o perfil de trabalho originado por antigos moradores da cidade de Venezia, do século XI e XII (Castelnuovo-Tedesco \& Sultanian, 2010, p. 110). Inclusive o termo antigo utilizado para fornelle era patere, comprovando a região de onde eram produzidas, pois patere provêm do dialeto veneziano que significa círculo. A função das fornelle segue igual ao tempo das patere, decorar edificações com símbolos significativos. De acordo com Rizzi (1987), provavelmente o seu formato e estilo deve-se a arte decorativa dos bizantinos e dos tecidos islâmicos, presentes na cidade de Venezia, pois encontrouse nas patere vestígios de cores iguais as utilizadas nas cerâmicas desses povos. Embora, ao longo do tempo, entre os anos de 1001-1200 e 1301-1400, esses símbolos ilustrados possuam algumas sutis diferenças, a essência da representação prevalece a mesma: pássaros com os 
pescoços entrelaçados, uma águia bicando um coelho ou uma lebre, dois pássaros bicando uma massa central de vegetação (Rizzi, 1974 e 1982; Castelnuovo-Tedesco \& Sultanian, 2010).

Quanto ao significado das ilustrações nas esculturas, as brigas entre animais, como águia e a lebre, representam o combate entre o bem e o mal [...] o triunfo da virtude sobre o vicio (Rizzi, 1987, p. 22). Segundo Frigerio (2010), também representam justiça, poder divino de Deus em pegar os culpados, acabar com o mal. Segundo Frigerio (2010), os símbolos das fornelles são inspirados nos textos bíblicos e aos Padres das Igrejas, mas também a tradição clássica e as crenças populares que se servem de símbolos e dos signos da natureza para falar das coisas do céu.

Criar joias refinadas com temáticas de obras raras para o público de poder aquisitivo elevado do Museu Stefano Bardini, responde as características do produto da moda de luxo proposta pelos autores (Dubois, Laurent e Czellar, 2001) pelos seguintes requisitos que formam as joias inspiradas nas obras da série Fornelle: excelente qualidade, alto apreço, a unidade e a raridade, estética relevante, tradição (o legado com o passado), caráter supérfluo; é dizer, o produto não responde a necessidade primaria, e seu valor não deriva de componentes funcionais, mas a própria satisfação de benefícios de outra natureza.

Esse público, amante da cultura italiana, reconhece e deseja obter o "estilo" italiano, ser reconhecido e celebrado em todo o mundo. Sem dúvida sinônimo de elegância e refinamento, de saber viver e brincar com a liberdade e criatividade de espirito, de acordo com a época (Colombo et al., 2013). No entanto, Alessi (2014), chama a atenção sobre o design italiano da atualidade, quanto a criatividade, 
já não ser apenas bela e poética senão também estratégica e decisiva.

Unir arte com moda, nesse sentido, escultura com joia, é valorizar a arte antiga e satisfazer o público amante da arte italiana. Outrossim, contempla a tendência do binômio arte-moda através da produção de acessórios de ouro. Tal como a própria etimologia de "joia" do latim locus que significa jogo, e no idioma francês e no idioma italiano joia é alegria - Joyau - Joie, gioia.

Cabe destacar, durante muito tempo, a joia somente interessou ao indivíduo como objeto material devido ao elevado valor dos materiais utilizados, como o ouro (Aranda Huete, 2015). Assim, a joia como talismã é uma dessas funções frente aos infinitos medos da humanidade advindos desde a antiguidade, pois pessoas ilustres eram retratadas com joias, eternizar significados, transmitir a mensagem adequada de insígnias de poder e proteção (Arbeleta Mira, 2014; Avellaneda, 2013; Ríos Lloret, 2015).

Nessa perspectiva, a moda é um sistema de signos que comunica o que se pensa do mundo. Afinal o usuário escolhe o que deseja mostrar na composição de seu vestuário. As crises, os medos, as complexidades, e os valores vigentes estariam manifestados também nas joias que o indivíduo adquire (Barthes, 2003). Ademais, de representar o signo de poder absoluto, também foi associada, por muito tempo, com virilidade por adornar esposa com joias valiosas para demonstração de riqueza e prestígio (Barthes, 2003). Do mesmo modo ocorre com os materiais selecionados para sua confecção, pois influenciam nos significados a transmitir ao público consumidor, além de utilizar a técnica e o processo do desenho para a criação de valores diferenciais na joalheria (Medina Gómez \& Hernandis Ortuño, 2012). 
Por conseguinte, a joia cumpre o papel de disfrutar o visual e de comunicar pensamentos. Neste caso, o usuário das joias, inspiradas nas fornelle, se identifica e passa a comunicar o mesmo significado daquele tempo em que foram fornadas as peças que atualmente estão em exposição na sala Chiostrina do Museu Stefano Bardini, isso se deve pela manutenção do entendimento dos signos de amor, esperança, força de vontade, justiça, paz e premissas de fé a Deus retratados nessas obras. Portanto, o significado da mensagem visual continua do mesmo modo, pois como afirma o autor Frigerio (2010), ao citar Alano di Lila do século XII "cada criatura do mundo para nós atua de espelho da nossa vida, da nossa mente, da nossa condição e é signo fiel da nossa sorte. "

\subsection{Joias Marco Baroni e a Serie Fornelle}

O joalheiro Marco Baroni, é conhecido pela realização de joias contemporâneas em ouro e ferro. Um exemplo de seu trabalho pode ser conferido pelo cantor americano Marc Anthony, portando um dos anéis, este visível na reportagem de Gaia De Vecchi, na coluna "Vogue Italia. Look del Giorno. Marc Anthony", publicada no dia 12 de agosto de 2011, ver Figura 3. O cantor de salsa é testemunha do desejo por peças com valores culturais advindos da arte antiga, neste caso, a italiana.

Figura 3: Anel by Marco Baroni adquirido pelo cantor Marc Anthony

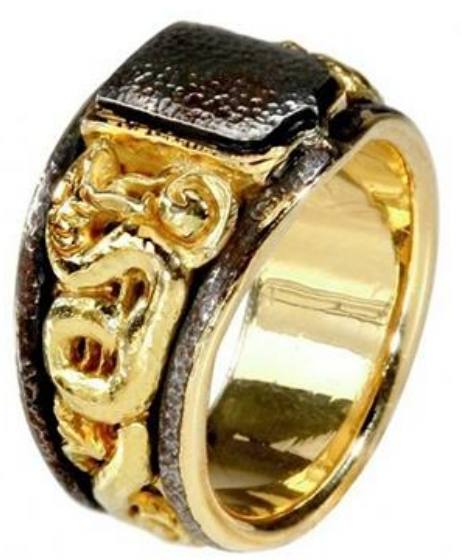

Fonte: Vogue (2018) 
Como foi dito, a ourivesaria do toscano representa a temática da arte antiga italiana com visão na tendência atual da moda, o binômio arte-moda, como é visualizada na Figura 4 com anel sobre a vida romana retratada em obelisco.

Figura 4: Anel de ferro e ouro inspirado na vida romana

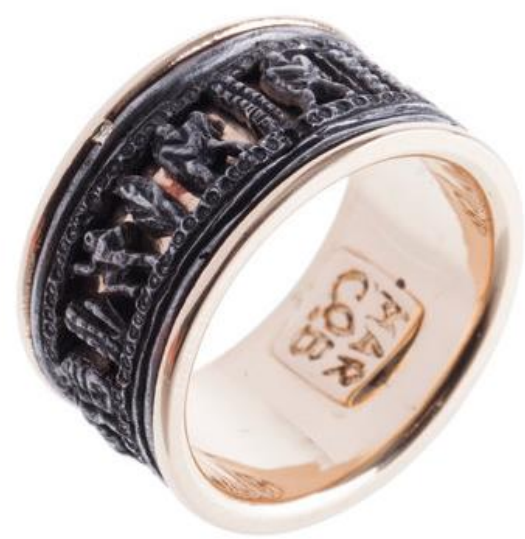

Fonte: Baroni (2018a)

De acordo com maestro toscano, morar rodeado por obras antigas, como na cidade de Florença, Itália, favoreceu seu repertorio visual para produzir joias. Estas também realizadas com diferentes materiais combinatórios, ouro, ferro, e pedras preciosas. Ademais da incorporação de distintas técnicas de produção e execução, como pode-se ver na Figura 5, com bracelete inspirado nas técnicas da joalheria fiorentina e anel inspirado no símbolo da cidade de Florença, o Giglio, motivo floral. 
Figura 5: Bracelete e anel inspirado em Florença
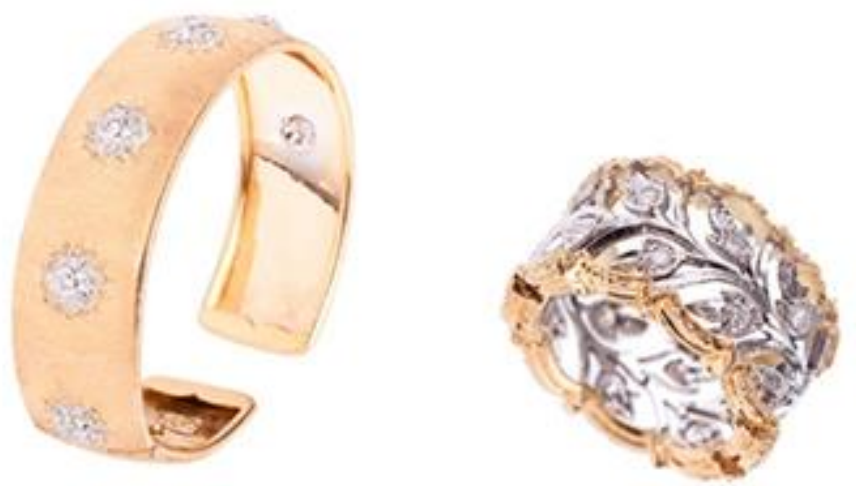

Fonte: Baroni, 2018b; 2018c

Para o projeto Museu Stefano Bardini - Serie Fornelle, ele optou unicamente pelo uso do ouro e técnica de ourivesaria. Segundo Balaguera (2013), esse metal provêm da palavra "aurum" em latim, que significa aurora brilhante, talvez por isso foi associado como o sol e utilizado em distintas culturas na evolução do tempo. Igualmente se atribuiu poderes curativos e mágicos, além de "seu valor como signo de ostentação e poder desejado pelos antepassados e maioria dos povos e culturas (Codina 2006, p.12). Inclusive, o ouro é "considerado como o mais precioso dos metais, é um símbolo de tudo aquilo que deseja o máximo valor, que resulte mais difícil de conseguir" (BruceMilford, 1997, p. 39). Desde os estudos antigos sobre alquimia, foi concebido como o metal mais puro e nobre, e ainda se relaciona com a eternidade e perfeição, além de imutável, e também usado para distanciar o mal (Barlanguera, 2013), enquanto na religião, como por exemplo "no cristianismo ortodoxo o ouro é um símbolo da luz celeste e da perfeição" (Biederman, 1993, p.337).

Diante de todas as informações, inclusive das sutis diferenças das patere e fornelle, quanto as" variações de qualidade e dimensões, manteve-se 0 desenho das esculturas compactos e as composições bem adaptadas a 
forma circular das esculturas rodas" (Swiechowsli, 1982, pp. 23-24). Desse modo, percebe-se o cuidado de Marco Baroni adaptar o desenho ao formato proposto e produziu pingentes de ouro com os motivos da série Fornelle, nota-se, em algumas, que preservou exatamente o formato de como estão atualmente essas obras antigas. Ver Figura 6.

Figura 6: Jóias inspiradas na Série Fornelle do Museu Stefano Bardini

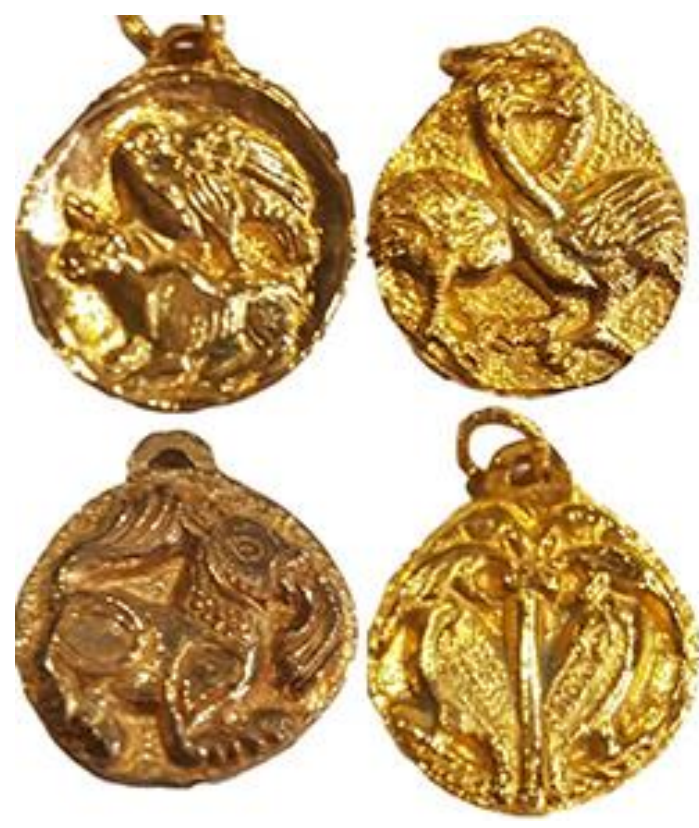

Fonte: Baroni, 2018d

O pingente pode ser utilizado em colares e pulseiras. Inclusive possui a versatilidade de ser aplicado em qualquer tipo de corrente. Devido à localização da joalheria de Baroni, ser na mesma rua do museu, facilita o cliente escolher o tipo de corrente para colocar o pingente da série Fornelle.

Ademais de receber sugestões do tipo de colar adequado ao formato de rosto, pescoço e ajustes das peças que o usuário deseja realizar.

\section{CONCLUSÕES, REFLEXÕES E SUGESTÕES}

"A joia se regulamentava pelo valor da riqueza, agora é pelo gosto. Em nosso tempo os acessórios se pensam como um conjunto da vestimenta [...] não se pretende mostrar riqueza" (BARTHES, 2003, p. 400-401). Por 
essa razão, a joia é um objeto que além da função decorativa possui a função simbólica, se preenche de significados do seu portador e os transmite (BALAGUERA, 2013, p. 115).

As imagens das esculturas circulares aqui apresentadas eram destinadas ao uso em Igrejas, de acordo com Frigerio (2010), possuem em relevo desenhos inspirados em textos bíblicos para melhor compreensão do diálogo dos padres. As joias inspiradas nas 18 fornelle, ainda possuem mensagens reconhecidas para diversos grupos da sociedade, por tratar de temas ainda atuais, tais como: o amor, a esperança, a força de vontade e a justiça. Como foi visto nas imagens apresentadas, o artista Marco Baroni, além de realizar joias inspiradas no desenho, materiais, técnicas de obras antigas, possui o papel principal de representar a cultura italiana. Sem dúvida as joias se dirigem a inter-relação das artes e a procura de novos talismãs para esperança (Avellaneda, 2013).

As joias fazem parte da história da humanidade desde seu princípio. O homem pré-histórico descobriu em seu entorno diferentes materiais, nos quais modificou para se transformar em ornamento que permitiram simbolizar dentro de seus grupos sociais, e o homem moderno ainda faz uso de determinados adornos, utiliza como emblema, como distintivo, ou como signo de poder de hierarquia (Balaguera, 2013 , p. 115). No caso apresentado, a joia espelha o desejo, o sentimento, o talismã de quem o porta.

A ideia de associar a arte, como a Série Fornelle, do Museu Stefano Bardini da cidade de Florença com a joalheria de Marco Baroni responde o que os autores afirmam sobre a moda italiana, tais como de Tartaglia \& Marinozzi (2006), quando informam que a criação de produto de moda, das grandes marcas de luxo italianas consideradas, são nascidos das criações estilísticas / designer, e não no estudo de uma exigência de consumidor. Inclusive apontam que o produto 
muda em constantes publicidades, o seu ponto de retorno é oposto: desaparece o efeito de raridade. Isto é confirmado pelo estudo do sociólogo Erner "a economia do consumo se reorganiza basicamente pela sedução e a caducidade acelerada das coisas. O gosto pelas novidades faz que os produtos se descartem rapidamente para novas formas" (Erner, 2010, p.180). As joias de Baroni, inspiradas da Série Fornelle do Museu Stefano Bardini, foram pensadas para um público de poder aquisitivo alto com gosto em exclusividade, e por isso teve um determinado tempo para venda, garantindo a raridade e valorizando ainda mais a obra.

Este tema apresentado neste artigo responde também aos estudos de Suárez Gaviria (2014), na constatação da necessidade de implementar soluções metodológicas para a aplicação de design na joalheria. De acordo com Moroni (2018) o uso de poucos instrumentos de estímulo criativo auxilia na produção rápida de ideias, inclusive nas tomadas de decisões projetuais. Assim, neste estudo, foi identificado quatro instrumentos de estímulo criativo para atender o binômio arte-moda: (i) brainstorm, chuva de ideias para integrar museu e moda contemporânea; (ii) analogia por transferir características de um objeto para outro, com objetivo de criar um novo; como neste exemplo de mesclar as esculturas da série fornelle com joias; (iii) Seis Chapéus, utilizada para facilitar a análise crítica do projeto, por responder diversos aspectos em diferentes perspectivas em torno ao público desejado, valorização do museu e cultura para gerar um produto de agrado ao público de alto poder aquisitivo e com interesse em significados e (iv) MESCRAI, onde cada letra traz uma ação, "M" (modificar), "E" (eliminar), "S "(substituir)," C" (combinar), "R" (readaptar), "A" (adaptar), "I" (inverter), aplicada no tipo de corrente para o pingente joia da série fornelle. Por essa razão, pensar em projetos que unem arte e moda são um exercício criativo 
benéfico para os estudantes que serão os futuros profissionais do mercado. Especialmente com a consciência de resgatar a história, a cultura com olhar nas obras artísticas de suas regiões, pois são um bom exemplo de eternizar memorias e transmitir legados.

De acordo com a diretora Antonella Nesi, o Museu Stefano Bardini é aberto ao público e possui interatividade com diversos setores de conhecimento devido ao vasto acervo de obras raras e originais. Toda a sua equipe de trabalho está à disposição para o atendimento de pesquisadores e sempre está aberta a receber propostas de utilização do espaço do museu com foco na reflexão, valorização das obras de mostras permanentes e de associalas as novas ideias com produtos da nossa contemporaneidade, como o caso da moda. Deste modo, se considera os museus um espaço de aprendizagem ideal para temática de projetos em salas de aulas nos cursos que abordam a estratégia para valorizar produtos, institutos, marcas e memória cultural, tais como de comércio internacional de obras, comunicação e design de moda. Em síntese, o caso citado da Itália em unir arte e moda, contribui como um bom exemplo para a valorização dos museus, suas obras de arte. Utilizadas como inspiração para a moda nos seus distintos setores, como a joalheria.

\section{AGRADECIMENTOS}

As autoras agradecem o financiamento de pesquisa internacional CAPES Brasil, Programa Ciência sem Fronteiras; ao apoio das Universidades UCA, UNDEF, USAL Argentina; a Diretora do Museu Stefano Bardini, Antonella Nesi, por disponibilizar do seu tempo, para indicar bibliografia e oportunizar liberdade para coletar material convidando o joalheiro Marco Baroni para descrição do seu 
trabalho e autorização dele para uso das imagens de suas joias aqui apresentadas; ademais as organizadoras deste volume da Revista Moda e Palavra, representantes do CONICET UBA Argentina, Profa. Dra. Laura Zambrini e Profa Dra. Daniela Lucena; a editora chefe Sandra Rech da UDESC Brasil e sua a equipe, Bruna Machado, Gabriel Bohn e revisores anônimos.

\section{REFERÊNCIAS}

ARANDA HUETE, Amelia Maria. La joya histórica como objeto de arte. Problemas de conservación. Geconservacion, n. 8, p. 154-160, 2015.

ALESSI, Chiara. Dopo gli anni Zero: il nuovo design italiano. Roma: Editori Laterza, 2014.

ARBELETA MIRA, Letizia. Las joyas reales de la Monarquía Hispánica: una aproximación iconográfica. Aurea quersonero: estudios sobre la plata iberoamericana XVI-XIX, 2014.

AVELLANEDA, Diana. De perfumes eu brillan y joyas que huelen: Objetos de la moda y talismãs de la fe.

Cuadernos de Estudios en Diseño y Comunicación. Ensayos. n. 44, p. 27-42, 2013.

BALAGUERA, Yina Lissete Satisteban. La influencia de los materiales en el significado de la joya. Cuadernos del Centro de Estudios en Diseño y Comunicación. Ensayos. n. 46 , p. $115-153,2013$.

BARTHES, Roland. The Rhetoric of the Image: Image, Musica, Text [trans. S. Heath, 1977]. London: Fontana, 1964.

BARTHES, Roland. De las joyas a la bisuteria. EI sistema de la moda y otros escritos. Buenos Aires: Paidos, 2003.

BARONI, Marco. Linea Marco B. Disponível em: http://www.marcobaronifirenze.com/linea-marco-b/. Acesso em: 20 mai. 2018a.

BARONI, Marco. Bracciale in oro ispirato su Firenze. Disponível 
em: http://www.marcobaronifirenze.com/gioielli/gioiellomarco-baroni-2-2-2/. Acesso em: 20 mai. 2018b.

BARONI, Marco. Giglio oro e anello di diamante. Disponível em:

http://www.marcobaronifirenze.com/gioielli/giglio-oroanello-diamante/. Acesso em: 20 maio 2018c.

BARONI, Marco. Alta Gioielleria Marco Baroni: gioielli serie Fornelle - Museo Stefano Bardini. Disponível em: http://www.marcobaronifirenze.com/. Acesso em: 20 mai. 2018d.

PENN, Gemma. Capítulo 13: Analise Semiótica de Imagens Paradas. p. 319-342. In BAUER, Martin.; GASKELL, George. Pesquisa Qualitativa com texto, Imagem e Som: Um manual prático. Rio de Janeiro: Vozes, 2000.

BECKER, Howard. Art worlds. Berkeley: University of California Press, 1982.

BIEDERMAN, H. Diccionario de símbolos. Buenos Aires: Paidos, 1993.

BRUCE-MILFORD, M. EI libro ilustrado de los símbolos y signos. Colonia del Valle, Mexico: Diana, 1997.

CASTELNUOVO-TEDESCO, Lisbeth, SOULTANIAN, Jack. Italian Medieval Sculpture. New York: Metropolitan Museum of Art, Yale University Press, New Haven and London, 2010.

CODINA, Charles. La Joyeria. Barcelona: Parramond, 2006. COLOMBO, Paul y CABALLOS, Alberto; MORA, Emanuela. Redactores de belleza - Art Crafts de la moda italiana. Venecia: Marsilio Publishers, 2013.

CRANE, Diana. Ensaios sobre moda, arte e globalização cultural. Organizadora: Maria Lucia Bueno. São Paulo: Ed. Senac, 2011.

DUBOIS, B., LAURENT, G., CZELLAR, S. Consumer rapport top luxury: Analyzing complex and ambivalent attitudes. Working Paper Series: 7, 36, Paris, 2001.

ERNER, Guillaume. Sociología de las tendencias. Barcelona: Ed. Gustavo Gilli, 2010.

FRIGERIO, Luca. Bestiario medievale, animali simbolici nell'arte cristiana. Milano: Ed. Ancora, 2010.

LAGHEZZA, E; LUCCHESE, F. Il design italiano attraverso moda, arte, cinema, grafica e música dal Secondo 
Dopoguerra al 1969. Dada Rivista di Antropologia postglobale, semestrale n. 1, 2016.

MARÍN, A. L. Sociología: el estudio de la realidad social. Pamplona: Ediciones Universidad de Navarra, S.A, 2011.

MEDINA GÒMEZ, Andrea; HERNANDIS ORTUÑO, Bernabé. La relación artesanía - diseño a través del producto jovauna persectiva histórico - técnica. Periodical Iconofacto, n. 10, p. 66-87, 2012.

MORONI, Yazmin Pamela da Silva. La Creatividad en la Toma de Decisiones Estratégicas. 2018. Tesis (mestrado). Universidad de la Defensa Nacional, Buenos Aires, Argentina

NESI, Antonella; SERAFINI, Francesca. Museo Bardini: Guida alla visita del museo a cura di Antonella Nesi. Musei del collezionismo storico, p.1-300, jan. 2011. Disponível em:https://issuu.com/piccoligrandimusei/docs/vf_museo_st efano_bardini_imp. Acesso em 21 jun. 2018.

PISCITELLI, A. M. Moda y sociedad. En: Balzano Silvia (compiladora). De la nueva cuestión social al cuidado y a la sociabilidad. Buenos Aires: EDUCA, 2011.

RIZZI, Alberto. Appunti per uno studio sulle patere veneziane, in Antichità viva, XIII, n. 6, p.32-43, 1974.

RIZZI, Alberto. 'Catalogue'. In Zygmunt Swiechowski, Alberto Rizzi, and Richard Hamann-MacLean, Romanische Reliefs von venezianischen Fassaden: 'Patere e Fornelle', pp. 29-226 Forschungen zur kunstgeschichte und christlichen Archaologie Wiesbaden, 1982.

RIZZI, Alberto. Scultura eterna a Venezia: corpus delle sculture erratiche all'aperto di Venezia e della sua laguna, 1987.

RÍOS LLORET, Rosa E. Centinelas del bienestar. Joyas protectoras en la pintura española del Renacimiento y Barroco. II Congreso Europeo de Joyería: Vestir las Joyas. Modas y modelos, 2015.

RUMSCHISKY TERMINIELLO, Ana María. El valor de la utilización de personajes famosos en la comunicación publicitaria: un análisis cuantitativo de precios para un producto de moda. 2009. Tese (Doutorado). Universidade Complutense de Madri, Madri, Espanha. 
SENSINI, Francesca. "Presque au-delà de la mode" La semiótica di genere nel linguaggio di Prada. Cahiers d'etudes italiennes, Società, culture, rappresentazioni. v. 1, n. 16, p. 135-155, 2013.

SUÁREZ GAVIRIA, Lorenza. Artesanía: História, concepto y dinámicas adaptativas a través de la cadena oro-joya. Revista académica e institucional de la UCPR, n. 94), p. 38-50, 2014.

TARTAGLIA, Annamaria; MARINOZZI, Gian. II lusso....magia e marketing. Presente e futuro del superfluo indispensabile. Milano: Franco Angeli, 2006.

VOGUE ITALIA. Look del Giorno. Marc Anthony. Disponível em: http:/ / www.vogue.it/uomo-vogue/look-delgiorno/2011/08/marc-anthony?refresh_ce=. Acesso em 25 maio 2018 . 